\title{
A Comprehensive Study of Micro-Hydropower Plant and Its Potential in Bangladesh
}

\author{
Jahidul Islam Razan, Riasat Siam Islam, Rezaul Hasan, Samiul Hasan, and Fokhrul Islam \\ Department of Electrical and Electronic Engineering, Islamic University of Technology, BoardBazar, Gazipur 1704, Bangladesh \\ Correspondence should be addressed to Jahidul Islam Razan, parthib_1090@yahoo.com
}

Received 23 October 2011; Accepted 14 November 2011

Academic Editors: B. Ma and B. Mwinyiwiwa

Copyright (๑) 2012 Jahidul Islam Razan et al. This is an open access article distributed under the Creative Commons Attribution License, which permits unrestricted use, distribution, and reproduction in any medium, provided the original work is properly cited.

Depletion of fossil fuel and the inability to meet the rising demand of electricity are some drawbacks for the economic development of Bangladesh. Carbon emission done by developed world is also troubling the country. This paper focuses on the potential of micro-hydropower plant in Bangladesh due to its numerous rivers and canals providing off-grid power to the remote areas and also to the areas that are still outside the main grid network. This paper reflects on the current energy scenario in Bangladesh, the need to explore green energy thus proving how the establishment of widespread micro-hydropower plant can help overcome the current power crisis and play a role in the economic progress of the country. The existing potential sites are mentioned and the means to identify new sites are outlined by performing hydrology studies, topographic studies, head calculations, turbine selection, and so forth.

\section{Introduction}

Bangladesh, with its emerging commerce and industries, is facing a daunting task to cope up with the power crisis. There is a lack of sufficient power generation capacity, and the existing national grid network is unable to power the whole nation. The rural and remote areas have a low-load demand but the electricity supply has been characterized by high transmission and distribution costs, transmission losses, and heavily subsidized pricing. The demand for power is increasing at a rapid pace although the generation of power has not increased at the same proportion. The gap between demand and supply of power is quite significant. The shortage of power generation capacity is estimated to be around $2500 \mathrm{MW}$ [1]. As a result, lack of a reliable electricity service has deterred foreign investment and held back economic growth. Energy consumption per capita is only $154 \mathrm{KWhr}$ which is much less than any of the developed countries [2]. In order to overcome the heavy power crisis and rapid depletion of available resources, Bangladesh needs to opt for alternate energy sources in the form of fossil fuels and renewable energy sources. The roadmap to energy security and energy sustainability will be achieved only if the economic and environmental aspects are taken into consideration.

Due to the huge contribution of $19 \%$ of the world's electricity power from both large and small power plants, hydro power is the most widely used renewable energy [35]. Department of Energy (DOE) defines large hydropower as power plants having generation capacity of more than $30 \mathrm{MW}$ [6]. Small hydropower plants are termed as having a generation capacity of $100 \mathrm{KW}$ to $30 \mathrm{MW}$ [6]. Microhydropower plants are defined as having a generation capacity ranges from $5 \mathrm{KW}$ to $100 \mathrm{KW}$ [4]. Water heads of 2 meters can be suitable to generate power efficiently with proper implementation of advanced technology. The energy problems in remote and hilly areas exist due to the uneconomical planning of the grid network $[3,4]$. Micro-hydropower provides low-cost solution for these remote sites. It provides a good solution for energy problems in remote and hilly areas where the extension of grid system is comparatively uneconomical [7].

In this paper, we have explored the potential of microhydropower plant as a source of renewable energy in order to tackle the power crisis of Bangladesh with in-depth analysis of Bamerchara micro-hydropower unit as a model. Section 2 
deals with the complete energy scenario in Bangladesh, Section 3 explains the necessity of exploration of alternative sources other than fossil fuel, Section 4 describes micro hydro as a source of green power generation, Section 5 demonstrates the parameters needed to be considered to explore new potential sites for micro-hydropower generation, Section 6 explains the economic considerations, Section 7 shows the potential micro-hydrosites already identified, Section 8 describes the socioeconomic impacts due to the establishment of micro-hydropower plant and economic feasibility of installing these plants, and Section 9 draws the conclusion.

\section{Energy Scenario in BD}

The main sources of power generation are hydropower, biofuels, coal, and natural gas. Large-scale hydropower ( $>40 \mathrm{MW}$ ) generation has been established which leads to resettlements thus losing agricultural lands. The nation has a high dependency on natural gas and hydropower for electricity generation but, as mentioned previously, low per capita energy consumption. The reserve for these fossil fuels is depleting at a high rate. At present the country does not have any energy security, and this is why after the fossil fuels are completely consumed, the country will face severe energy crisis. That is a huge concern for the mass people of the country. On the other hand, the country is seriously affected by the natural calamities. Thus, energy sustainability is another important aspect that should be taken into consideration. All these factors lead to the inability to consider energy sustainability. Generating more power from fossil fuels to overcome the gap between demand and supply has made it even more difficult to attain energy sustainability due to their high depletion rate. As a result, the circumstances are such that alternative energy sources other than fossil fuels should be taken into consideration to have a secured and sustainable energy future.

The current reserves for fossil fuels in Bangladesh should be analyzed. Bangladesh has modest hydrocarbon resources and rich renewable energy sources especially in the form of traditional energy. The Natural gas reserves in Bangladesh are likely to be depleted before 2020 which will bring the power generation at a halt. In Barapukuria, the deposits of Coal may supply about $250 \mathrm{MW}$ [8]. When the demands for electricity would exceed $11000 \mathrm{MW}$, emergency measures should be taken to conserve energy, to achieve high-efficiency plants, explore gas, and coal reserves to prevent the inevitable disaster due to the lack of power supply. The Government of Bangladesh is planning to tackle the situation by renting power systems and coal-fired systems. But more importantly energy supplies using RETs must be developed and utilized.

To fulfill the demands as estimated for 2020, power generation should be increased and government is providing the following incentives as mentioned in the Renewable Energy Policy 2008 and Government initiatives on RET 2009 [9].

(i) First are the policy sets targets for developing renewable energy resources to meet five percent of the total power demand by 2015 and ten percent by 2020 . (ii) Second is creating enabling environment and legal support to encourage the use of renewable energy.

(iii) Third is implementing policies for mitigation of environmental issues arising out of use of renewable energy.

(iv) Fourth is processing of grid-connected renewable energy projects.

(v) Electricity generated from renewable energy projects, both in public and private sectors, may be purchased by power utilities or any consumer through mutual agreement (up to $5 \mathrm{MW}$ ).

(vi) To promote renewable energy in power sector, all renewable energy equipments and related raw materials in producing renewable energy equipments will be exempted from charging 15\% VAT.

(vii) Bangladesh Bank has sanctioned a revolving fund of 200 Crore Tk. for renewable energy projects.

(viii) In addition to commercial lending, a network of microcredit support system will be established especially in rural and remote areas to provide financial support for purchases of renewable energy equipment.

\section{Necessity of Exploration of Alternative Sources Other than Fossil Fuel}

Bangladesh has very minimal contribution to global warming in comparison with many other developed countries. Bangladesh shares less than $0.1 \%$ of global emissions of $\mathrm{CO}_{2}$ compared with $24 \%$ of the USA and emits about 0.19 tons of $\mathrm{CO}_{2}$ per capita [1]. Major areas of emissions are the industries and power plants. In the rural areas burning of wood, dung, and crop residues causes air pollution and results in severe health problems considerably for women working indoors. These pollution and emissions lead to environmental degradation which in turn causes increased climate risks and natural disasters.

Although fossil and biofuels contribute to such pollution, there has been recent information that Bangladesh has over 2 billion of low-sulphur content coal reserves. Also there are reserves for natural gas and oil, where oil reserves are estimated to be 56.9 million barrels [10]. More initiatives to explore such reserves should be taken but unfortunately the economic potential and efficient use of these resources are limited due to lack of exploitation and distribution facilities. The large reserves of oil are present in Bangladesh but still $90 \%$ of its oil demands are met through imports [8]. For the exploration and exploitation of these resources, required funds and technologies are highly insufficient. Foreign intervention is always not profitable in terms of economic and environmental aspects. Leakage and other accidents in the past in such reserves have created a suspicion for their acceptability. Taking into consideration the economic and environmental issues related to fossil and biofuel reserves, it is quite obvious that a more feasible alternative should be sought. 
Renewable energy sources are abundant in Bangladesh. Already some of them have been implemented and some are yet to be tried. $3.6 \mathrm{GW}$ of electricity is generated annually, $6 \%$ comes from large-scale hydropower, and the remaining 94\% comes from thermal (natural gas and oilfired) [1]. Further exploitation of hydropower is expected to be limited to small and mini-hydropower plants due to the flat terrain and numerous canals with estimated potential of about $250 \mathrm{MW}$ [8]. Biomass, solar, wind, and micro-hydropower plants are some other potential sources of renewable energy. Most of the developing countries are taking into consideration environment friendly alternatives and in context Bangladesh government has allocated 20\% of total public sector investment on energy sector in their last budget along with other incentives as mentioned previously [9]. It is of utmost importance that alternative sources of energy are explored. It has been already mentioned that the factors governing this emergency need include dependency on fossil fuels, depletion of reserves, limitation on exploiting new reserves, and economic and environmental impacts.

\section{Micro-Hydro as a Source of Green Power Generation}

Micro-hydropower in comparison to other nonconventional energy sources includes the following.

(a) Selection of Potential Sites. Hilly areas with natural water falls on the dam-toe or canal drops are suitable sites for micro-hydropower plants. For such site selection long range studies are not required. Sites for biomass plants are usually located by taking into consideration the availability of water, raw materials for biogas generation, free open space, total space required, minimum gradient, water table, distance from wells, and grid. Wind power plants are situated at a certain place where wind velocities are very high and relatively constant all over the year. Monthly and annual average velocities should be similar year in year out. Suitable locations for solar power plants are areas consisting of flat terrain with no high raised buildings and trees nearby [11].

(b) Problems while Connecting to the National Grid. Microhydropower plants produce nearly constant input power. The only variation results in change of seasons due to the seasonal climate changes and water flow rate. So overall for a certain season, the power is almost constant. The power fed to the main national grid network is very smooth with no such nonlinearities that are present in other sources of energy. Power fed to the grid produced by solar and wind energy consists of fluctuations on voltage and frequency levels, harmonic distortion, nonlinearities, and other abnormalities. This usually occurs due to the variation in wind velocities and solar light intensity all throughout the day. In numerous occasions the power needs to be put off grid because of certain factors going below the threshold level during power transmission and distribution [11].

(c) Problems Governing Operation, Maintenance, and Control. Micro-hydropower is easy to operate and there is no need for rigorous maintenance, whereas wind power plant causes severe noise pollution, teething troubles, and poor performance due to operation and maintenance problems. Major challenge relies on designing signal conditioner, computer interfacing, and software for system operation. The pulsating input power pattern for the wind power station is another major problem. Moreover, there are various problems while handling biogas: pollutants such as effluent slurry, accumulation of volatile fatty acids, gas forming methanogenic bacteria, and leakage of gas from gas holder. Other problems include drop in Ph level and failure of digester [11].

(d) Affects on the Environment. Micro-hydropower, wind, and solar power plants are clean and pollution free. They are basically very environment friendly sources. Although wind power plants create noise pollution, biomass causes environmental pollution and it does not meet the pollution control regulation, whereas micro-hydropower maintains the ecological balance and stream flow of the rivers. The impacts on the environment of each energy sources have been studied thoroughly and the enhancement of these technologies has been considered [11].

The estimated power output is governed by the following equation: $P=Q \times H \times 7.83$, where $P$ is the theoretical amount of power in $\mathrm{KW}, Q$ is the discharge flow rate in $\mathrm{m}^{3} / \mathrm{s}$ and $H$ is the water head in metres. The equation is an approximation relied on theoretical studies. The actual power output varies depending upon pressure losses through the inlet and penstock also upon the turbine and generator efficiency. Another factor is the reduction of stream flow leading to the penstock due to environmental and fisheries constraints. The factors mentioned reduce the amount of energy produced.

The aforementioned comparison shows that microhydropower is a potential source of energy. Full utilization of this energy will result in environmental friendly generation of power from canals and rivers.

Micro-hydropower projects have been successfully implemented to provide standardized technologies for offgrid decentralized power to these remote hilly areas and small villages. Power to some mountainous villages has brought about major socioeconomic development. Microhydropowers have replaced diesel generators and implemented in a hybrid system in line with solar power [11]. These power plants have been used for direct mechanical energy for small industries and agriculture. Small-scale projects include battery charging, welding workshop, crop processing, grain milling, home, farm, ranch, and village. Another small-scale implementation may be to power homes in remote areas without a dam. The most significant use of micro hydropower is the off-grid decentralization of its surrounding areas. Micro-hydropower meets smooth and stable power supply. Thus, the surrounding areas of individual generating stations can be easily powered and it is very economical. This will reduce consumer demand on the national grid network. Moreover, micro-hydropower stations can always be fed to the national grid. Microhydropower projects are generally considered to be more environmental friendly than both large hydro and fossil 
fuel-powered plants. With all these advantages, micro-hydropower can be implemented as principle renewable sources for sustainable development especially in developing countries like Bangladesh.

\section{Parameters Needed to Be Considered to Explore New Potential Sites}

5.1. Choosing a Micro-Hydrosite. Micro-hydropower sites should be chosen by taking into consideration the terrain and availability of high stream flow rate. Micro-hydropower plants are to be situated in hilly areas where there are natural falls, on the canal drops or at the dam-toe. As mentioned before long range studies are not required for such site selection. Many people need electricity in places that are beyond the reach of power lines. Some even look at the creek that flows through their property, tapping the energy of the water either for their own use or to sell to potential buyers. Regardless of the reason for wanting to develop a micro-hydroproject, an appropriate location is required for the project. Choosing a site is one of the most important steps in development, as it will largely determine the amount of energy that can be developed and the complexity of site development. Some factors to be considered are outlined as follows [12].

5.1.1. Topographic Maps. Mapping of an area is one of the prime tools for site selection. Information such as the length of pipelines, transmission lines, and possible water head can be obtained from such maps. Other relevant information is the source of the stream and its direction of flow, roads to access the site, and also the size of the drainage area. Some of the sources for mapping include the $1: 50,000$ scale national topographic system (NTS) maps, 1:20,000 scale TRIM maps, local forestry maps, and custom maps based on recent photos. Mapping of the possible regions provides detailed accuracy for site feasibility with increase in cost.

5.1.2. Site Hydrology. Hydrology study includes exploration of the origin of the stream flow and its destination. It also includes measurement of stream flow direction and flow rate. Although this study is time consuming, but it facilitates proper planning. The available tools to determine the hydrology of a potential site include maps, stream flow data, and water quality studies.

5.1.3. Water Quality Studies. Studies should be performed to obtain relevant data regarding the level and variety of sediments like silt, fine sand, gravel, rocks, floating debris, and dissolved chemicals. Basically the data are used to determine the material for the equipment that comes in contact with water and also to take necessary precautions for the sediments that flow along the stream. There are other hydrological matters related to water quality studies that need to be considered.

5.1.4. High Head. The water should be allowed the maximum vertical displacement and the shortest path to travel.
The maximum vertical displacement accounts for the high water head. Large water head accounts for higher power produced. For high head, the turbine speed will be large; thus a small turbine can be opted for a given power output. However, at high heads the pipe pressure ratings and the strength of the pipe materials should be considered for design. Water must be allowed in the shortest route to travel; otherwise it will require long penstock which is quite costly. Longer pathway for the water to travel will reduce its flow rate due to fluid and other forms of friction.

5.1.5. Lines or Load Should Be at a Close Proximity. For ongrid generation, the site should be closer to the distribution and transmission line. Also for off-grid generation, the loads should be at a close proximity. This ease in distributing the power will result in low transmission costs. It is to be noted that for on-grid micro-hydroplant it is cost effective to connect to the 11 to $33 \mathrm{KV}$ lines. Voltage levels greater than that increase the connection the cost.

5.1.6. Turbine. The selection of type of turbine is one of the problems in design of hydroplant. The characteristics, parameters, and classification involved facilitate the choice of turbine. There are two methods of selection [6].

(1) Graphical Selection. It is the various types of turbine, graphs relating discharges, head work, model test result, and test report. Turbine is selected according to the head and discharge values [6].

(2) Analytical Selection. According to the head and discharge values, the turbine parameters are calculated using the formula

$$
P_{t}=\frac{P}{\eta},
$$

where $P$ is power in $\mathrm{KW}$, and $\eta$ is the system efficiency including turbine, generator, and gear box efficiency.

Then specific speed can be calculated as

$$
N s=\frac{(N \times P t) 0.5}{H}\left(\frac{5}{4}\right)
$$

where $P_{t}$ is turbine output in KW, and $N$ is the rated speed in rpm.

Runner Diameter. After performing model test and selecting design of turbine, the actual runner diameter is determined by the manufacturer. The following formula can be used [6]:

$$
D_{r}=\left(0.0242 N_{s}\right)^{(2 / 3)},
$$

where $D_{r}$ is runner diameter, and $N_{s}$ is specific speed in rpm

$$
D_{2}=\frac{84.6 \times D_{r} \times H^{0.5}}{N}
$$


where $D_{2}$ is Discharge diameter and $N$ is speed of turbine. Turbines can be classified according to their specific speed:

(1) high head turbine and low specific speed (Pelton),

(2) medium head turbine and medium specific speed (Francis),

(3) low head turbine and high specific speed (Kaplan and Propeller).

Turbines are designed as Dam Base, Canal fall, Run-off River, and Hilly region depending upon specific site conditions [11].

Kaplan Turbine. Large quantity of water at low head is suitable for such turbines. These turbines range from head of 30 metre and specific speed from 255 to 860 (Power in KW) [13].

Francis Turbine. Moderate quantity of water at medium head is suitable for such turbines. These turbines range from head of 55 metre to 240 metre and then specific speed from 51 to 255 (Power in KW) [13].

Pelton Turbine. These turbines range from 8.5 to 30 (Power in KW) for single jet Pelton Wheel and from 30 to 51 (Power in KW) for Pelton Wheel with double jet. The head value ranges above 240 metre [13].

Bulb Turbine. Large rivers with high flow are suitable for such turbines. These are more economic than Kaplan turbine. These turbines range from head of 3 to 23 metres and specific speed from 200 to 40 (Power in KW) [13].

PIT Turbine. These are modified version of the Kaplan turbine that works on head value below 15 metre [13].

S-Type Turbine. These turbines are smaller version of Kaplan turbine with horizontal inlet. These turbines have water head as low as 1 metre to 15 metre. Specific speed ranges from 50 to 500 (Power in KW) [13].

Cross-Flow Turbine. These turbines are subset of impulse turbine. The hand ranges lower than Pelton turbine with values up to 180 metre and specific speed up to $2 \mathrm{MW}$ [13].

Penstock Diameter. The diameter is calculated using design discharge, head, and plant capacity using this formula [6]:

$$
\frac{\Pi \times D_{2}}{4}=\frac{Q_{d}}{V} .
$$

This formula gives the diameter of penstock [13].

5.2. Generators. The micro-hydropower can be installed with induction generator and synchronous generator. For both on-grid and off-grid modes induction generator gives advantages such as low cost and robust construction. However, synchronous generator is used in off-grid mode.
Synchronous Generator. Generally for commercial purpose synchronous machine is widely used. Generators driven at low speeds by prime-movers like water turbines will have salient pole construction having large number of projected poles [13].

Induction Generator. This needs very little auxiliary equipment and can be run in parallel with generator without hunting at any frequency. For IG speed variation of primemover is less important. Power fed to the grid varies from 0.94 to 0.97 p.u. due to variation in line losses while the generator output almost remains constant. With the terminal capacitors, there is marginal increase in power fed to the grid resulting in improved efficiency [13].

Low Environmental Impact. When choosing the site, care must be taken to avoid unacceptably high environmental impacts such as damage to fish populations, endangered species, or air quality [13].

Power Reliability. The Power output is directly dependent upon head and discharge. Head and discharge depend upon rainfall and also stream flow in rivers and canals. The estimation of river flow and rainfall determines the reliability of Power output from the micro hydro-powerplant [13].

\section{Economic Considerations}

6.1. Economic Feasibility. There are some donor agencies or global financial institutions which contribute for green technology and reduction of carbon emission. Green technology fund can be obtained from World Bank Climate Investment Funds [14], The Least Developed Countries Fund (LDCF) [14], and The Adaptation Fund. Besides these available funds, there are also some internationally recognized mechanisms, which create opportunity for developing nations to generate funds for implementing any green project in their country. Two of such mechanisms are CDM (Clean development mechanism) and Carbon finance. The Clean Technology Fund is a climate fund that will aim to promote low-carbon economies by helping to finance deployment in developing countries of commercially available cleaner energy technologies through investments in support of credible national mitigation plans that include low-carbon objectives. The Strategic Climate Fund will help more vulnerable countries develop climate-resilient economies and take actions to prevent deforestation. The Least Developed Countries Fund (LDCF) was established under the United Nations Framework Convention on Climate Change (UNFCCC) at it seventh session in Marrakech and is managed by the Global Environment Facility. The fund addresses the special needs of the 48 Least Developed Countries (LDCs), which are especially vulnerable to the adverse impacts of climate change. The Adaptation Fund has been established by the Parties to the Kyoto Protocol of the UN Framework Convention on Climate Change to finance concrete adaptation projects and programmes in developing countries that are Parties to the Kyoto Protocol. 
The CDM (Clean development mechanism) allows emission-reduction (or emission removal) projects in developing countries to earn certified emission reduction (CER) credits, each equivalent to one ton of $\mathrm{CO}_{2}[15,16]$. These CERs can be traded and sold and used by industrialized countries to meet a part of their emission reduction targets under the Kyoto Protocol. The World Bank Carbon Finance Unit (CFU) uses money contributed by governments and companies in OECD countries to purchase projectbased greenhouse gas emission reductions in developing countries and countries with economies in transition [17]. The emission reductions are purchased through one of the CFU's carbon funds on behalf of the contributor, and within the framework of the Kyoto Protocol's Clean Development Mechanism (CDM) or Joint Implementation (JI). The role of the Bank's Carbon Finance Unit is to catalyze a global carbon market that reduces transaction costs, supports sustainable development and reaches, and benefits the poorer communities of the developing world.

As Bangladesh is a developing nation which suffered most for the climate change and COP15 conference which took place in Copenhagen called Bangladesh as most vulnerable country of the world, micro-hydropower project will be encouraged by all quarters in this country and thus Bangladesh will also get funds from all the above mentioned fund raising body.

Estimating the Preliminary Cost. Costs for the micro-hydropower plant project include initial costs related to study conducted for proper site selection and project development; construction expenses regarding design and purchasing of equipments; and annual costs related to maintenance, taxes, rentals, and so forth.

Initial Costs. These include costs for site selection, feasibility studies, environmental impact assessments, permits, obtaining land rights, financing fees, energy purchase agreements, and interconnection agreements.

Feasibility Studies. The purpose of this study is to assess whether to proceed with the project. Feasibility studies involve environmental assessment, hydrology assessment, preliminary designs, and detailed cost estimates.

Construction Costs. These include necessary equipments, civil works, access roads, transmission lines, interconnection fees, and others related to setting up the project.

Services. Costs for the work force required to build the plant. Costs include hiring engineers, managers, and labourers, also providing them other facilities like food, lodging, and so forth.

Costs for Equipments. These include purchasing various equipments like protection system, control system, turbine, generators, and so forth. Also costs include transportation, installation, and maintenance of these equipments.
Annual Costs. These includes operation and maintenance costs for the complete project and include administrative costs such as salaries, rentals, and fees.

\section{Micro-Hydrosites in Bangladesh}

In February 1981, the Water Development Board and Power Development jointly carried out a study on the assessment of Small/Mini-Hydropower Potential in the country [11]. The committee explored 19 prospective sites for possible installation of small hydropower plants. Later in the month of April 1984, Six Chinese experts visited Bangladesh and they identified 12 potential sites for development of minihydropower plant. Out of these sites, only Mahamaya Chara, near Mirersharai, close to Dhaka-Chittagong highway was identified as the best site for development of small hydro. Following are the sites that were identified (Table 1) $[9,11]$.

In 2004 sustainable Rural Energy, Local government Engineering Department has explored some potential microhydrosites in Chittagong which is listed in Table 2.

Most of the potential sites are situated in the Chittagong hill tracts (CHTs). It requires potential utilization of hydropower and indigenous technical knowledge to utilize the existing opportunities in the CHT areas. Decentralization of micro-hydropower units with local implementation and management through self-reliance and the use of local natural resources will have significant impact on the remote tribal rural development.

Mr. Aung Thui Khoin set such an instance by setting up a micro-hydroplant. The unit was constructed with wooden turbine and making an earthen dam on the flowing Hara Khal at remote hilly region of Monjaipara, Bandarban. About $10 \mathrm{~kW}$ electricity is being generated by this microhydropower unit that has illuminated 40 households of that village. That led to an agreement between LGED and innovator Mr. Aung Thui Khoin for a month long study. The objectives of the study were identification of microhydropower potential sites within the hilly regions and promotion of indigenous technologies for development of hydropower. Possible integration with power generation and irrigation schemes was also under consideration.

From the study, some prospective sites for micro-hydropower development in three districts of CHT region were identified with the help of LGED officials, local communities, and head man. The potential sites are given as follows in Table 3.

"Feasibility Study on R\&D of Renewable Energy (Solar, Wind, Micro-Mini-Hydro)" has been carried out by the Institute of Fuel Research Development (IFRD) of Bangladesh council of Scientific and Industrial Research (BCSIR). Various data are collected through the related instruments regarding the Micro-Mini-Hydrostudy at two selected places of (1) Shailopropat, Bandarban, and (2) Madhobkundu, Moulibhibazar.

The collected data and information are analyzed on various aspects at RET laboratory of IFRD. On the basis of analysis of collected data up to June 2001, it is expected that 5 to $10 \mathrm{~kW}$ capacity Micro-Hydropower plant at Sailipropat, 
TABLE 1: Potenial small hydrosites identified by BPDB and BWDB.

\begin{tabular}{|c|c|c|}
\hline District & Name river/chara/stream & Potential of electrical energy in KW \\
\hline Chittagong & 1. Foy's Lake & 4 \\
\hline Chittagong & 2. Choto kumira & 15 \\
\hline Chittagong & 3. Hinguli Chara & 12 \\
\hline Chittagong Hill Tracts & 4. Sealock & 81 \\
\hline Chittagong & 5. Lungi Chara & 10 \\
\hline Chittagong & 6. Budia Chara & 10 \\
\hline Sylhet & 7. Nikhari Chara & 26 \\
\hline Sylhet & 8. Ranga pani Gung & 616 \\
\hline \multirow{2}{*}{ Jamalpur } & \multirow{2}{*}{ 9. Bhugai-kongsa at 2 miles U/S of Nalitabari P.S } & $69 \mathrm{Kw}$ for 10 months \\
\hline & & $48 \mathrm{Kw}$ for 2 months \\
\hline \multirow{2}{*}{ Jamalpur } & \multirow{2}{*}{ 10. Marisi at Dukabad near Jhinaigati Thana Head Quater } & $35 \mathrm{Kw}$ for 10 months \\
\hline & & $20 \mathrm{Kw}$ for 2 months \\
\hline \multirow{6}{*}{ Dinajpur } & 11. Dahuk at Burabari & 24 \\
\hline & 12. Chawai at U/S of Chawai L.L.P & 32 \\
\hline & 13. Talam at U/S of Talam L.L.P & 24 \\
\hline & 14. Pathraj at Fulbari & 32 \\
\hline & 15. Tangon at D/S of Nargun L.L.P & 48 \\
\hline & 16. Punarbhaba at Singraban & 11 \\
\hline \multirow{2}{*}{ Rangpur } & 17. Bhuri khora Chikli at Nizbari & 32 \\
\hline & 18. Fulkumar at Raigang Bazar & 48 \\
\hline
\end{tabular}

TABle 2: Potential micro-hydrosites in Chittagong.

\begin{tabular}{lcccc}
\hline \multirow{2}{*}{ Site } & \multicolumn{2}{c}{$\begin{array}{c}\text { Expected power generation } \\
\text { in KW Industry }\end{array}$} & \multicolumn{3}{c}{ Socio economic infrastructure within 1 km } \\
Souse hold & School/mosque/bazaar/clinic & Small industry \\
\hline Nunchari Tholipara, Khagrachari & 3 & 100 & 3 & 1 \\
Bandarban & 30 & 200 & 5 & 2 \\
Bangchari, Bandarban & 25 & 600 & 12 & 5 \\
Liragoan, Bandarban & 20 & 500 & 8 & 3 \\
Kamalchar, Rangamati & 20 & 150 & 6 & 3 \\
Thang Khrue Rangamati & 30 & 300 & 3 & - \\
Monjaipara Bandarban & 7.5 & 50 & 8 & 3 \\
\hline
\end{tabular}

TABLE 3: Potential micro-hydrosites identified by LGED Officials.

\begin{tabular}{lllll}
\hline Name of the canal with location & Sectional area $(\mathrm{m})^{2}$ & Lowest flood level $(\mathrm{m})$ & Highest flood level $(\mathrm{m})$ & Power potential $(\mathrm{kW})$ \\
\hline Nunchari Tholi Khal in Khagrachari & 11 & 0.06 (May) & 3 & 5 \\
Sealock Khal in Bandarban & 25 & 0.15 (April) & 4 & 30 \\
Taracha Khal in Bandarban & 35 & 0.1 (April) & 6 & 20 \\
Rowangchari Khal in Bandarban & 30 & 0.1 (April) & 5 & 10 \\
Hnara Khal in Kamal Chari, Rangamati & 20 & 0.15 (May) & 4.20 & 10 \\
Hnara Khal in, Hang Khrue Chara Mukh, & 25 & 0.12 (May) & 4 & 30 \\
Rangamati & 15 & 0.50 & 1 & 10 \\
Monjaipara micro-hydropower Unit & - & - & - & 10 \\
Bamer Chara irrigation Project & & & \\
\hline
\end{tabular}

Banderban, and 10 to $20 \mathrm{~kW}$ capacity Micro-Hydropower Plant at Madhobkundu, Moulibhibazar, can be installed for electricity generation are given in Table 4.

Bamerchara project is the first demonstration microhydropower unit in Bangladesh. This project was initially implemented in order to provide irrigation facilities to 355 ha land. This unit has helped us to get insight knowledge and practical experience in harnessing micro-hydropower. It has enabled the local farmers to use the electricity from that unit for daytime irrigation, so a considerable amount of power is 

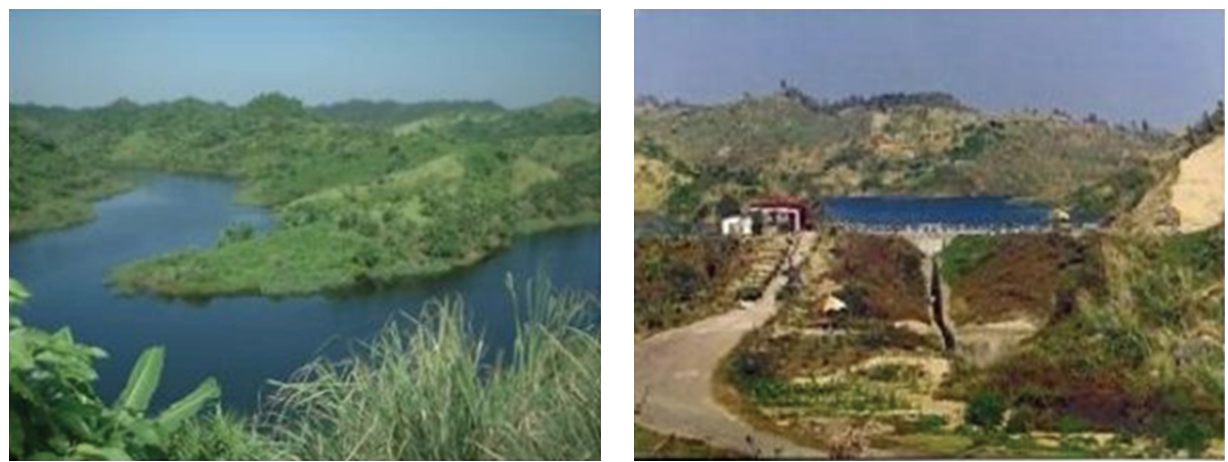

Bamerchara Lake
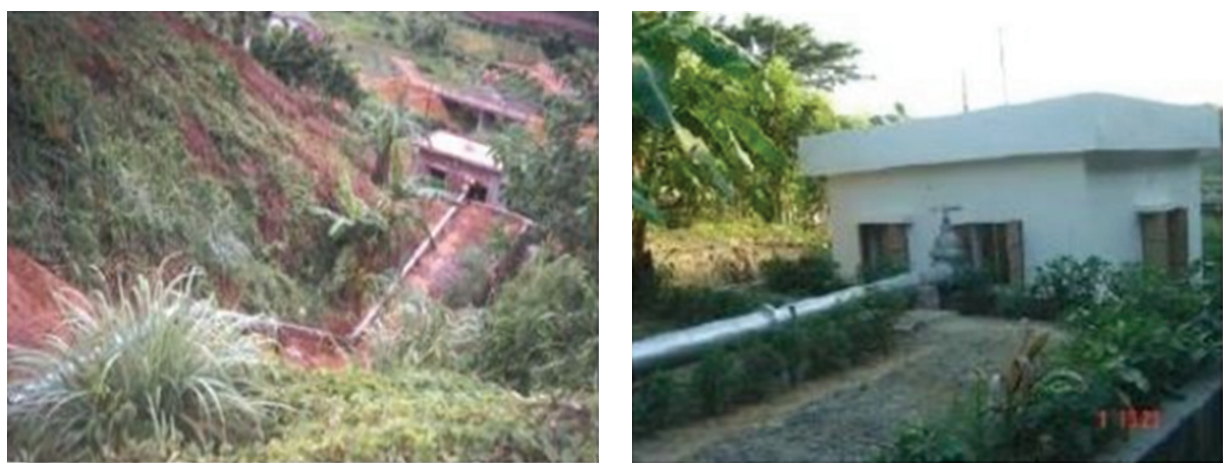

Bamerchara micro-hydropower unit

FiguRE 1: Bamerchara Lake and Bamerchara micro-Hydropower Unit.

TABLE 4: Potential sites identified by IFRD of BCSIR.

\begin{tabular}{llllll}
\hline Name of water falls & $\begin{array}{l}\text { Average discharge } \\
\text { (Litre/sec) }\end{array}$ & $\begin{array}{l}\text { Approximate } \\
\text { duration of flow } \\
\text { (months) }\end{array}$ & $\begin{array}{l}\text { Probable fall for } \\
\text { hydropower generation } \\
\text { (meter) }\end{array}$ & $\begin{array}{l}\text { Electrical power } \\
\text { (KW) }\end{array}$ & $\begin{array}{l}\text { Annual energy } \\
\text { production (kWh) }\end{array}$ \\
\hline Sailopropat, Banderban & 100 & 12 & 6 & 5 & 43,800 \\
Madhobkundu, Moulvibazar & 150 & 12 & 10 & 15 & 131,400 \\
\hline
\end{tabular}

saved. The remaining power could be stored in a battery bank or could be used at grain mills or cooking.

Salient Feature of Bamerchara Micro-Hydropower Unit. Estimated capacity of the system was $10 \mathrm{~kW}$. Salient feature of the unit has been illustrated as follows:

(i) turbine type: cross flow,

(ii) penstock: $52 \mathrm{~m}$,

(iii) design flow: 150 liter/sec,

(iv) net head available: $6 \mathrm{~m}-10 \mathrm{~m}$,

(v) preferred governor: flow control (manual),

(vi) electrical output: 4-6 KW, $50 \mathrm{~Hz}, 3$ phase voltage, 220 $\mathrm{V} / 440$.

Considering water head of 11 meters and flow rate of $150 \mathrm{~L} / \mathrm{s}$, it was estimated that maximum $10 \mathrm{~kW}$ hydropower could be generated from "Bamerchara" site (Figures 1 and 2 ). But when irrigation starts, water head falls rapidly.

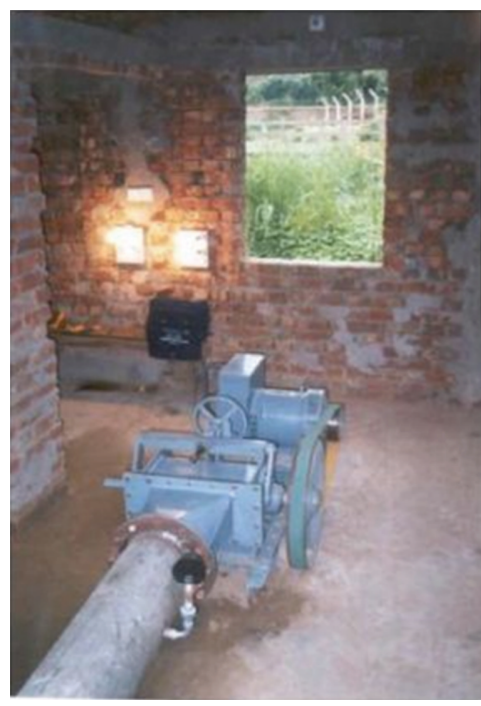

Figure 2: Bamerchara Micro-Hydropower Unit. 


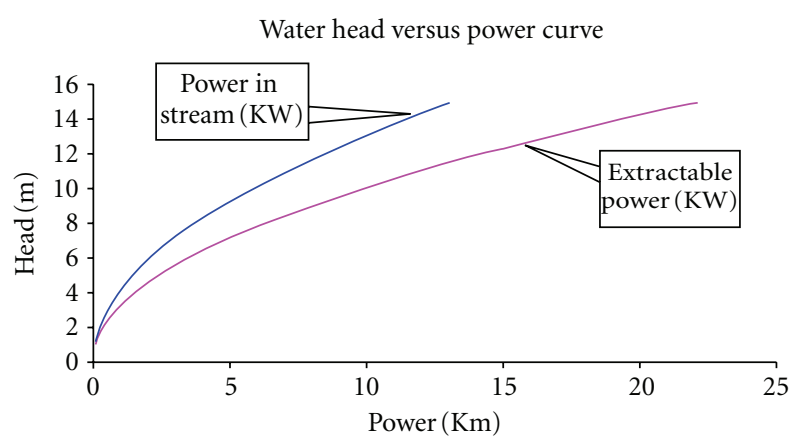

FIgURE 3: Relationship between water head and power.

Consequently full power generation was not possible. Furthermore, about $41 \%$ potential energy was lost by the penstock, turbine, and generator and transmission line. Figure 3 illustrates relationship between water head and extractable hydropower from a stream.

\section{Socio Economic Impact}

Bangladesh is mainly an agricultural country. Almost the whole population is dependent upon agriculture either directly or indirectly. Unfortunately, Bangladesh has never enjoyed $100 \%$ electrification [9]. As a result irrigation has hampered a great deal due to the power crisis.

In total Bangladesh has 232 rivers including the main rivers and their branches. So, if proper selection criteria are maintained, it will not be very difficult to find the potential sites where runoff MHP plant can be set up. The electricity produced from these sites can play a very vital role in facilitating the local farmers to have proper irrigation facility [18].

Most of the identified places so far are in the hilly areas where mainly the tribal people have their habitat. Currently most of them are out of electrification facility. Exploration of further potential sites and proper utilization of the existing sites will create opportunity to bring them under electrification. Besides improving their standard of life it will enable them to start small-scale industries in those remote areas [19]. Hence, there will be opportunities for jobs and self-employment. It would also encourage them to start home-based industry through the availability of three-phase power [18]. Production of electricity in remote areas will save huge transmission and associated infrastructural cost [18]. Also, these hilly areas being an attractive tourist spot undoubtedly tourism will flourish due to the availability of power. Tourism has also been a good source of revenue for Bangladesh.

Shrimp cultivation is one of the main sources of foreign revenue of the country [20]. But due to shortage of electricity, it has been very difficult to apply the modern techniques of cultivation. Potential river sites with run-off MHP facility will enable the local farmer to apply semi-intensive and intensive method of cultivation.

\section{Conclusion}

In this paper, the current power crisis of Bangladesh has been discussed. Necessity of exploring energy from alternative sources and impact of micro-hydro as an alternative source has been presented. Since micro-hydropower plant requires terrain and availability of high stream flow rate, so, it has a good potential in the north-eastern hilly regions of Bangladesh which is also evident from the presented data. Due to the abundance of rivers and canals, Bangladesh has a good run-off river micro-hydropotential but it is yet to be explored. Parameters in order to set up new microhydroplants have been discussed. A primary guideline of economic feasibility and a way of raising necessary fund have been proposed.

No development strategy can be implemented without power. Bangladesh is still very much dependent on fossil fuel for power generation. But, the country has limited resources which are likely to be finished very soon. On top of that, burning of fossil fuels has very negative environmental consequences. Now-a-days, the whole world is much more concerned than ever before about not only the depletion of various energy resources but also environmental degradation caused by the existing pattern of fossil fuel use. As a populous country with small energy resources, our concern is even greater. Proper consideration of parameters to explore potential sites can also inspire the interested individuals and can work as an incentive to establish micro-hydroplant for local use. Due measures of establishing decentralized small-scale water power or micro-hydroschemes can prove it as an effective eco-friendly source of power generation, as internationally funds for green energy are available that can be a great appreciation for government to explore this option also.

\section{References}

[1] S. N. Uddin and R. Taplin, "A sustainable energy future in Bangladesh: current situation and need for effective strategies," in Proceedings of the 2nd Joint International Conference on Sustainable Energy and Environment (SEE '06), Bangkok, Thailand, November 2006.

[2] M. R. Hasan, M. J. I. Razan, M. S. Shahriar, R. S. Islam, and S. M. Ferdous, "Nuclear power-an inevitable option for most vulnerable countries from the perspective of environmental degradation," Journal of Selected Areas in Renewable Energy. In press.

[3] N. Raman, I. Hussein, and K. Palanisamy, "Micro hydro potential in West Malaysia," in Proceedings of the 3rd International Conference on Energy and Environment: Advancement Towards Global Sustainability (ICEE '09), pp. 348-359, December 2009.

[4] I. Hussein and N. Raman, "Reconnaissance studies of micro hydro potential in Malaysia," in Proceedings of the International Conference on Energy and Sustainable Development: Issues and Strategies (ESD '10), pp. 1-10, June 2010.

[5] J. K. Kaldellis, "The contribution of small hydro power stations to the electricity generation in Greece: technical and economic considerations," Energy Policy, vol. 35, no. 4, pp. 2187-2196, 2007. 
[6] M. Borota, Mini Hydro Power Plants_Green Power for Users, Directorate for Water Management, Ministry of Agriculture, Forestry and Water Management, Merita Borota, Serbia, 2008.

[7] S. P. Adhau, R. M. Moharil, and P. G. Adhau, "Reassessment of irrigation potential for micro hydro power generation," in Proceedings of the IEEE International Conference on Sustainable Energy Technologies (ICSET '10), Kandy, Sri Lanka, December 2010.

[8] J. M. A. Munim, M. M. Hakim, and M. Abdullah-Al-Mamun, "Analysis of energy consumption and indicators of energy use in Bangladesh," Economic Change and Restructuring, vol. 43, no. 4, pp. 275-302, 2010.

[9] Bangladesh Renewable Energy Report by Asian and Pacific Centre for Transfer of Technology Of the United NationssEconomic and Social Commission for Asia and the Pacific (ESCAP).

[10] K. Page, Asia \& Pacific Review 2003/04: The Economic and Business Report, Kogan Page Publishers, 2003.

[11] M. A. Wazed and S. Ahmed, "Micro hydro energy resources in Bangladesh: a review," Australian Journal of Basic and Applied Sciences, vol. 2, no. 4, pp. 1209-1222, 2008.

[12] J. Croockewit, Developing Micro Hydro in British Columbia, BC Hydro Engineering, 2004.

[13] S. P. Adhau, "A comparative study of micro hydro power schemes promoting self sustained rural areas," in Proceedings of the 1st International Conference on Sustainable Power Generation and Supply (SUPERGEN '09), pp. 1-6, April 2009.

[14] D. Nassiry and D. Wheeler, "A green venture fund to finance clean technology for developing countries," Center for Global Development Working Paper no. 245, 2011.

[15] S. Subbarao and B. Lloyd, "Can the clean development mechanism (CDM) deliver?” Energy Policy, vol. 39, no. 3, pp. 1600-1611, 2011.

[16] S. Mishra, S. K. Singal, and D. K. Khatod, "Sustainable energy development by small hydropower with CDM benefits in India," International Journal of Ambient Energy, vol. 32, no. 2, pp. 103-110, 2011.

[17] S. Ahmad, M. Z. A. A. Kadir, and S. Shafie, "Current perspective of the renewable energy development in Malaysia," Renewable and Sustainable Energy Reviews, vol. 15, no. 2, pp. 897-904, 2011.

[18] A. Kopp, "How to use rural electricity in a productive way," NADEL MAS-Cycle 2008-2010, April 2010.

[19] M. Alam Hossain Mondal, L. M. Kamp, and N. I. Pachova, "Drivers, barriers, and strategies for implementation of renewable energy technologies in rural areas in Bangladesh-An innovation system analysis," Energy Policy, vol. 38, no. 8, pp. 4626-4634, 2010.

[20] A. Ahmed, "Prospects, Importance, Problems and Impacts of Shrimp Cultivation in Bangladesh: A Literature Review," May 2010, http://ssrn.com/abstract=1612845. 

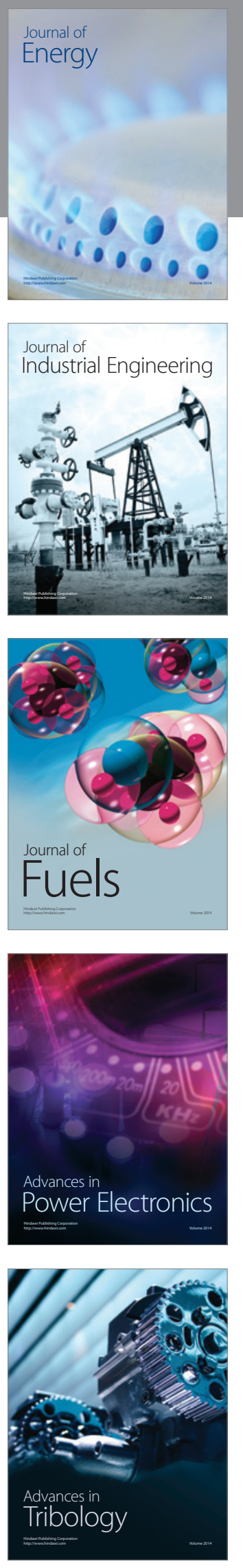
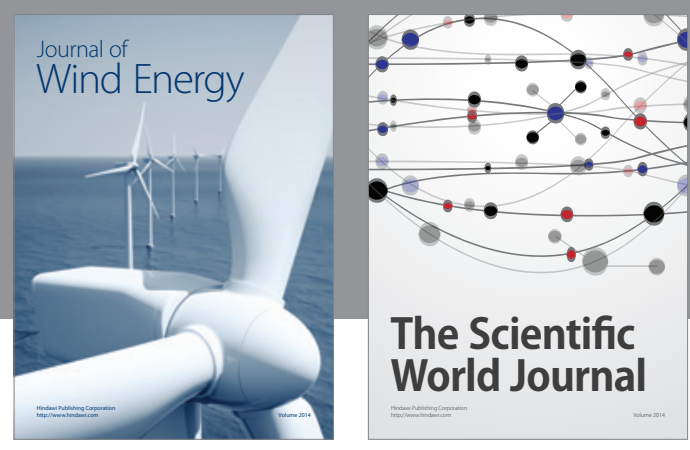

The Scientific World Journal

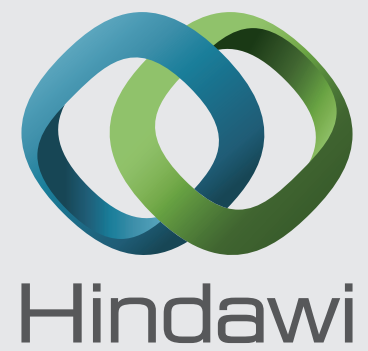

Submit your manuscripts at http://www.hindawi.com
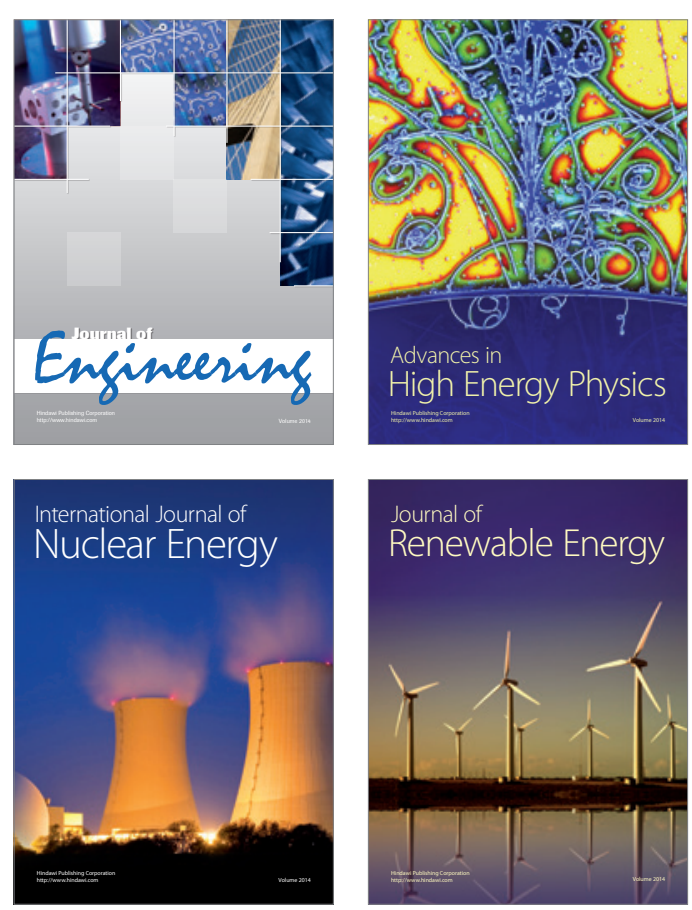

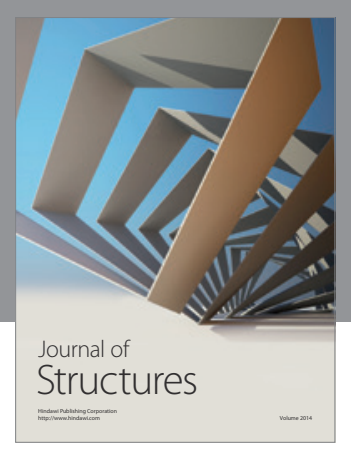

Rotating
Mechinery
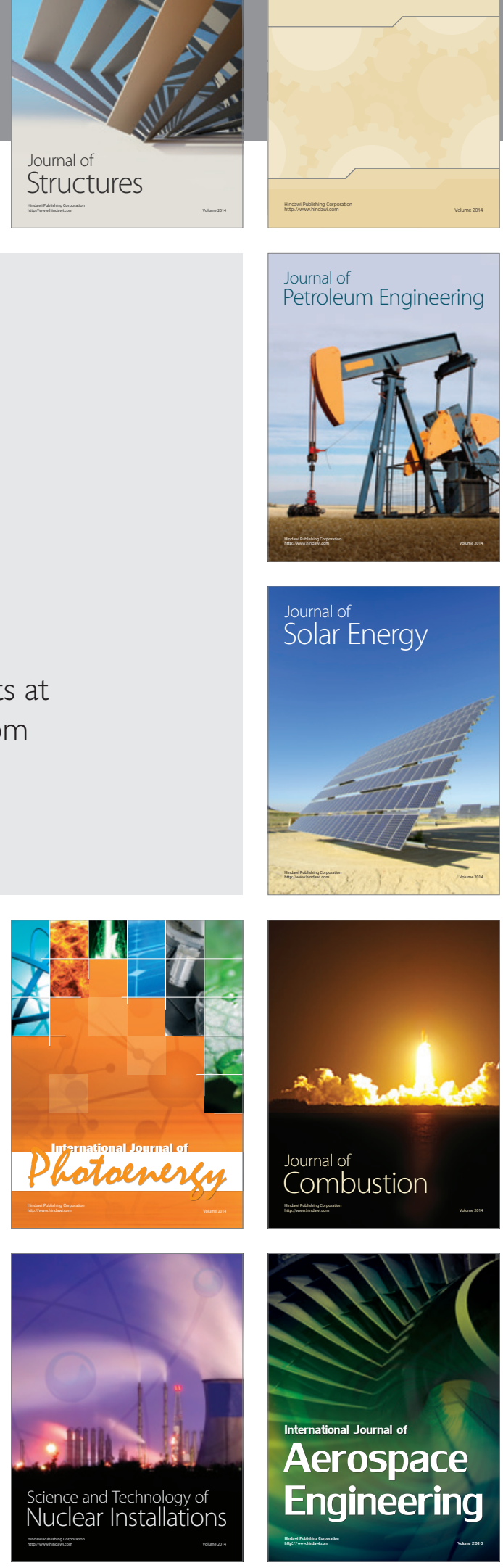